\title{
Methylation and transcriptome analysis reveal lung adenocarcinoma-specific diagnostic biomarkers
}

Rui Li ${ }^{1}$, Yi-E Yang ${ }^{2}$, Yun-Hong Yin ${ }^{1}$, Meng-Yu Zhang ${ }^{1}$, Hao Li ${ }^{1 *}$ and Yi-Qing Qu ${ }^{1 *}(\mathbb{0}$

\begin{abstract}
Background: DNA methylation can regulate the role of long noncoding RNAs (IncRNAs) in the development of lung adenocarcinoma (LUAD). The present study aimed to identify methylation-driven IncRNAs and mRNAs as biomarkers in the prognosis of LUAD using bioinformatics analysis.

Methods: Differentially expressed RNAs were obtained using the edge R package from 535 LUAD tissues and 59 adjacent non-LUAD tissues. Differentially methylated genes were obtained using the limma R package from 475 LUAD tissues and 32 adjacent non-LUAD tissues. Methylation-driven mRNA and IncRNA were obtained using the MethylMix R package from 465 LUAD tissues with matched DNA methylation and RNA expression and 32 non-LUAD tissues with DNA methylation. Gene ontology and ConsensusPathDB pathway analysis were performed to identify functional enrichment of methylation-driven mRNAs. Univariate and multivariate Cox regression analyses were performed to identify the independent effect of each variable for predicting the prognosis of LUAD. Kaplan-Meier curve analysis of DNA methylation and gene expression might provide potential prognostic biomarkers for LUAD patients.
\end{abstract}

Results: A total of 99 methylation-driven mRNAs and 17 methylation-driven IncRNAs were obtained. Univariate and multivariate Cox regression analysis showed that 6 IncRNAs (FOXE1, HOXB13-AS1_2, VMO1, HIST1H3F, AJ003147.8, ASXL3) were retrieved to construct a predictive model associated with overall survival in LUAD patients. Combined DNA methylation and gene expression survival analysis revealed that 4 InCRNAs (AC023824.1, AF186192.1, LINC01354 and WASIR2) and 8 mRNAs (S1PR1, CCDC181, F2RL1, EFS, KLHDC9, MPV17L, GKN2, ITPRIPL1) might act as independent biomarkers for the prognosis of LUAD.

Conclusions: Methylation-driven IncRNA and mRNA contribute to the survival of LUAD, and 4 IncRNAs and 8 mRNAs might be potential biomarkers for the prognosis of LUAD.

Keywords: Lung adenocarcinoma, Methylation-driven IncRNA, Methylation-driven mRNA, Biomarkers, Overall survival rate

\section{Background}

Lung cancer is the leading cause of cancer-related death worldwide [1]. Lung adenocarcinoma (LUAD) accounts for $45-55 \%$ of non-small-cell lung cancer (NSCLC), with a 5-year overall survival rate of less than 15\% [2]. Due to the heterogeneity of lung adenocarcinoma, it is still a

\footnotetext{
*Correspondence: doctorlihao@163.com; quyiqing@sdu.edu.cn

${ }^{1}$ Department of Respiratory and Critical Care Medicine, Qilu Hospital

of Shandong University, Jinan 250012, China

Full list of author information is available at the end of the article
}

great challenge to develop successful individual-based treatment [3]. Therefore, there is an urgently need to identify effective and promising biomarkers in predicting the prognosis of LUAD.

Genetic aberrant expression is crucial for cancer etiology, and the joint effect of both genetic and epigenetic changes facilitates the development of human cancer [4-6]. DNA methylation acts as the key element in epigenetic modifications and plays a significant role in the regulation of cellular functions and carcinogenesis [7-9]. Epigenetic modification, especially DNA methylation, 
can provide a novel horizon to explore new biomarkers in predicting the prognosis of cancer [10-14]. A large number of studies have demonstrated that DNA methylation can regulate the expression of lncRNA, and this phenomenon may be associated with the prognosis of lung cancer [15]. For instance, the lncRNA AFAP1-AS1 acts as an oncogene in NSCLC, while its expression is tightly regulated by DNA methylation, which might provide prognostic and diagnostic values for NSCLC patients [16].

MethylMix, an algorithm implemented in the $\mathrm{R}$ programming environment, identifies disease-specific hyperand hypomethylated genes [17]. Currently, few studies on methylation-driven genes have been reported [18]. Recently, a study based on using MethylMix to explore methylation-driven genes for predicting the prognosis of LUAD was reported; however, they only obtained information about methylation-driven mRNA [19]. In this study, DNA methylation and RNA-Seq data were extracted from The Cancer Genome Atlas (TCGA) database, and we used the MethylMix $\mathrm{R}$ package to obtain LUAD-specific methylation-driven lncRNA sequences. Furthermore, a Cox survival predictive model with 6 lncRNAs was constructed to predict the diagnosis and prognosis of LUAD. Finally, the combined effect of DNA methylation and gene expression survival analysis was examined, which might provide a novel insight to explore methylation-driven IncRNA and mRNA for predicting the prognosis of LUAD.

\section{Methods}

\section{Data retrieving and analyzing}

Methylation and RNA-Seq expression data were retrieved from LUADs from the TCGA database. The methylation data were downloaded from 475 cancer tissues and 32 noncancer tissues from the Illumina Human methylation 450k platform. The RNA-Seq data (level 3), including mRNA and lncRNA expression, were retrieved from 535 cancer tissues and 59 noncancer tissues from the IlluminaHiSeq_RNASeq platform. First, on the basis of "limma R" packages in R with absolute fold change $(\log 2)>0$ and adjusting the false discovery rate (FDR) to a $P$ value $<0.05$, we obtained aberrant methylated genes. The methylation difference of the mean of the $3000 \mathrm{bp}$ (base pair) sites upstream of the gene was analyzed to identify the differential level of methylation in the gene promoter [19-22]. We analyzed the differential level of methylation in the promoter of genes by using the limma $R$ package [23]. Then, based on the "edge R" packages in R with absolute fold change $(\log 2)>3$ and adjusting the false discovery rate (FDR) to a $P$ value $<0.01$ to correct the statistical significance of multiple experiments, we retrieved differentially expressed mRNA and lncRNA. MethylMix is a kind of $\mathrm{R}$ statistical package for integrating DNA methylation data and RNA expression data to identify methylation-driven genes in kinds of cancers [17, 2426]. Filtering or eliminating missing value genes is the preprocessing common step when running MethylMix $\mathrm{R}$ software [17]. In this present manuscript, we filtered or eliminated missing value genes and intersected DNA methylation data with RNA expression data for matching. Finally, there were a total of 465 LUAD samples with matched DNA methylation and RNA expression and 32 non-LUAD samples with DNA methylation data for entering the MethylMix R package. Then, calculated the correlation between DNA methylation level and RNA expression to find significantly negatively related genes, a beta mixture model was constructed for the degree of methylation of samples, Wilcoxon rank test was used to calculate differential methylation in LUAD and adjacent non-LUAD samples. Finally, the methylation-driven mRNA and lncRNA was obtained. Since the data were directly obtained from the TCGA database, no approval was required from the local ethics committee.

\section{Functional enrichment analysis of methylation-driven mRNA in LUAD}

To determine the function represented in the methylation-driven mRNA, we used the Database for Annotation, Visualization and Integrated Discovery (DAVID) (http://david.abcc.ncifcrf.gov/) to perform a functional and enrichment analysis on the methylation-driven mRNA by using GO and ConsensusPathDB analysis. In the GO analysis, a $P$ value of less than 0.05 was considered statistically significant. Furthermore, the GOCircle and GOChord plotting functions of the GOplot R package were used to allow data from expression analysis and data from functional annotation enrichment analysis. ConsensusPathDB (http://cpdb.molgen.mpg.de/) is an online software program that includes binary and complex signaling, gene regulatory and drug-target interactions, and biochemical pathways. $P<0.05$ was considered statistically significant.

\section{Construction of a differentially methylated, IncRNA-related predictive model in LUAD}

We identified the differentially methylated lncRNA associated with overall survival with $P<0.05$ to act as prognostic methylation IncRNA candidates for multivariate Cox regression analysis. On the basis of the median risk score, LUAD patients were divided into two cohorts, high-risk cohorts and low-risk cohorts. Receiver operating curves were used to test the effect of the lncRNA signature (high risk vs low risk) on overall 
survival. We analyzed the receiver operating curve by calculating the area under the curve (AUC) under the binomial exact confidence interval to reveal prognostic biomarkers for predicting survival in LUAD.

\section{Combined methylation and gene expression survival analysis}

To further explore the effect of methylation level and gene expression level of the same methylation-driven key gene on LUAD patient prognosis, we performed a combined methylation and gene expression survival analysis to identify potential methylation-driven mRNAs and methylation-driven lncRNAs for predicting the prognosis of LUAD patients. Therefore, a Kaplan-Meier curve was performed. $P<0.05$ was regarded as statistically significant.

\section{Results}

\section{Identification of methylation-driven mRNA and IncRNA} in LUAD

A total of 99 mRNAs and 17 lncRNAs were identified to be associated with DNA methylation using MethylMix criteria. The methylation-driven mRNAs and IncRNAs are shown in Tables 1 and 2, respectively. We constructed a mixed model and performed a Wilcoxon rank test for determining differential methylation $(\operatorname{logFC}>0, P<0.05$, Cor $<-0.3)$. Figure 1 shows that two methylation-driven mRNAs (ZNF454 and ZNF471) (Fig. 1f, g) and two methylation-driven lncRNAs (TUSC8 and LINC00676) (Fig. 1h, i) have significant negative correlations between methylation and gene expression levels. In Fig. 1, the distribution of the methylation degree shows that ZNF454 (Fig. 1b), ZNF471 (Fig. 1c), and LINC00676 (Fig. 1e) are hypermethylated in LUAD patients and hypomethylated in the normal group, while TUSC8 (Fig. 1d) is hypomethylated in LUAD patients and hypermethylated in the normal group. A heat map of methylation-driven mRNAs and lncRNAs is shown in Fig. 2a, b. A flow diagram of the exploration of methylation-driven mRNA and lncRNA in LUAD is shown in Fig. 1a.

\section{Enrichment analysis of methylation-driven mRNAs in LUAD} Gene ontology analysis showed that there were 5 GO terms (regulation of transcription, DNA-templated; transcription factor activity, sequence-specific DNA binding; nucleic acid binding; transcription, DNA-templated; metal ion binding) with significant differences $(P<0.05)$, and the highest GO biological process was "GO:0006355 regulation of transcription, DNA-templated" (Fig. 3a, c).
The GOChord plot shows the top 30 methylation-driven mRNAs with their related GO terms (Fig. 3b). Figure 4 shows that 11 pathways (Generic Transcription Pathway, Benzene metabolism, RNA Polymerase II Transcription, Gene expression (Transcription), Platinum Pathway, Pharmacokinetics/Pharmacodynamics, Phase II-Conjugation of compounds, Sulfation Biotransformation Reaction, Estrogen metabolism, Glutathionemediated detoxification, Cytosolic sulfonation of small molecules, Drug metabolism-other enzymes-Homo sapiens (human)) were considered statistically significant $(P<0.05)$. Furthermore, pathway analysis showed that the methylation-driven mRNAs were most enriched in the Generic Transcription Pathway, RNA Polymerase II Transcription and Gene expression (Transcription) pathways $(P<0.01)$ (Fig. 4$)$. The pathway analysis is shown in Table 3.

\section{Construction of a predictive model of six differentially methylated IncRNAs in LUAD}

Univariate Cox regression analysis was performed first to identify the prognosis associated with differentially methylated genes in LUAD, incorporating 10 methylation genes that were conspicuously associated with overall survival $(P<0.05)$. Next, multivariate Cox regression was used and showed that six lncRNAs were eventually selected to construct a predictive model. We used the linear combination of the expression of the 6 lncRNAs to construct the predictive model. The relative coefficients weighted in the multivariate Cox regression were as follows: survival risk score $=(3.0040 \times$ expression value of FOXE1 + $1.0226 \times$ expression value of HOXB13AS1_2+1.0540 $\times$ expressionvalueof $V M O 1+1.0050 \times$ expression value of HIST1H3F $+(-3.0925) \times$ expression value of AJ003147.8+1.4791 × expression value of ASXL3). The multivariate Cox analysis is shown in Table 4.

\section{Risk groupings and ROC curve analysis}

As shown in the heat map, the expression of six prognostic methylation genes was profiled (Fig. 5a). Based on the median risk scores, a total of 449 samples of complete survival information were divided into a highrisk group $(n=224)$ and a low-risk group $(n=225)$. We used the Kaplan-Meier curve with a log-rank statistical examination to perform survival analysis. As shown in Fig. 5b, patients in the low-risk group had conspicuously better overall survival than those in the high-risk group (Fig. 5b). The receiver operating characteristic (ROC) curve was analyzed to test the influence on the 6-lncRNA signature associated with overall survival in LUAD (Fig. 5c). 
Table 1 Methylation-driven mRNAs

\begin{tabular}{|c|c|c|c|c|c|c|c|}
\hline mRNA & Normal mean & Tumor mean & $\log \mathrm{FC}$ & $P$ Value & Adjusted-P & Cor & Cor P-value \\
\hline ECSCR & 0.651549745 & 0.777875207 & 0.255663395 & $6.97 \mathrm{E}-21$ & $1.03 E-18$ & -0.401694346 & $1.85 \mathrm{E}-19$ \\
\hline TBX4 & 0.3491894 & 0.503087408 & 0.526799315 & $7.58 \mathrm{E}-21$ & $1.12 \mathrm{E}-18$ & -0.353891186 & $3.64 \mathrm{E}-15$ \\
\hline TIE1 & 0.559830867 & 0.675047137 & 0.269997212 & $1.21 \mathrm{E}-20$ & $1.79 \mathrm{E}-18$ & -0.406629901 & $6.08 \mathrm{E}-20$ \\
\hline $\mathrm{NEFH}$ & 0.254444122 & 0.435542374 & 0.775464224 & $1.40 E-20$ & $2.07 \mathrm{E}-18$ & -0.321798888 & $1.16 \mathrm{E}-12$ \\
\hline ACVRL1 & 0.398975345 & 0.517535129 & 0.375357195 & $3.26 \mathrm{E}-20$ & $4.82 \mathrm{E}-18$ & -0.386877674 & $4.73 \mathrm{E}-18$ \\
\hline USHBP1 & 0.419199887 & 0.525059456 & 0.324842471 & $3.63 E-20$ & $5.37 \mathrm{E}-18$ & -0.323007247 & $9.42 \mathrm{E}-13$ \\
\hline ERN2 & 0.264647925 & 0.387648278 & 0.550673914 & $3.92 \mathrm{E}-20$ & $5.80 E-18$ & -0.450728621 & $1.20 E-24$ \\
\hline COX7A1 & 0.560388444 & 0.666059579 & 0.249224026 & $9.41 E-20$ & $1.39 E-17$ & -0.342569242 & $3.00 E-14$ \\
\hline SULT1C4 & 0.176980042 & 0.3113128 & 0.814778224 & $2.45 E-19$ & $3.62 \mathrm{E}-17$ & -0.375338318 & $5.28 \mathrm{E}-17$ \\
\hline ART4 & 0.531234199 & 0.652680788 & 0.297029548 & $2.53 E-19$ & $3.75 E-17$ & -0.425340294 & $7.44 \mathrm{E}-22$ \\
\hline HIST1H3E & 0.313889479 & 0.456138176 & 0.539214244 & $1.45 \mathrm{E}-18$ & $2.15 E-16$ & -0.390470196 & $2.19 \mathrm{E}-18$ \\
\hline ZNF492 & 0.077650427 & 0.196364234 & 1.33846642 & $1.18 \mathrm{E}-17$ & $1.75 E-15$ & -0.378866342 & $2.55 \mathrm{E}-17$ \\
\hline ZNF728 & 0.138731042 & 0.290955121 & 1.068506001 & $1.32 \mathrm{E}-17$ & $1.95 \mathrm{E}-15$ & -0.346356662 & $1.50 \mathrm{E}-14$ \\
\hline S1PR1 & 0.33644215 & 0.424456445 & 0.33525806 & $4.34 \mathrm{E}-17$ & $6.43 E-15$ & -0.375495078 & $5.11 \mathrm{E}-17$ \\
\hline MUC13 & 0.657841786 & 0.551979674 & -0.253125507 & $4.44 \mathrm{E}-17$ & $6.57 \mathrm{E}-15$ & -0.402604202 & $1.51 \mathrm{E}-19$ \\
\hline CCDC8 & 0.360671572 & 0.480500959 & 0.413853596 & $8.99 E-17$ & $1.33 \mathrm{E}-14$ & -0.389064482 & $2.96 \mathrm{E}-18$ \\
\hline ZNF578 & 0.281145557 & 0.394615614 & 0.489130794 & $1.12 E-16$ & $1.66 \mathrm{E}-14$ & -0.459621578 & $1.11 \mathrm{E}-25$ \\
\hline FES & 0.424918825 & 0.49946057 & 0.233183531 & $2.74 \mathrm{E}-16$ & $4.05 E-14$ & -0.370960412 & $1.29 \mathrm{E}-16$ \\
\hline ASCL1 & 0.096716299 & 0.200703748 & 1.053236604 & $2.98 \mathrm{E}-16$ & $4.41 \mathrm{E}-14$ & -0.331763879 & $2.08 \mathrm{E}-13$ \\
\hline ALG1L & 0.461379719 & 0.287062126 & -0.684591589 & $3.14 \mathrm{E}-16$ & $4.65 E-14$ & -0.466908378 & $1.49 E-26$ \\
\hline ELF3 & 0.462412193 & 0.359973363 & -0.361289285 & $4.47 E-16$ & $6.61 E-14$ & -0.45067724 & $1.22 \mathrm{E}-24$ \\
\hline TMEM88 & 0.583625618 & 0.738189625 & 0.338948249 & $7.89 E-16$ & $1.17 E-13$ & -0.390308898 & $2.27 \mathrm{E}-18$ \\
\hline GSTM5 & 0.356896303 & 0.481942079 & 0.433354815 & $1.13 E-15$ & $1.68 \mathrm{E}-13$ & -0.353462769 & $3.95 E-15$ \\
\hline $\operatorname{IRX} 1$ & 0.098629887 & 0.220552417 & 1.161024783 & $1.21 E-15$ & $1.79 E-13$ & -0.344157687 & $2.24 \mathrm{E}-14$ \\
\hline ZNF454 & 0.183616121 & 0.338501411 & 0.88246912 & $1.44 \mathrm{E}-15$ & $2.13 \mathrm{E}-13$ & -0.602235321 & $3.13 \mathrm{E}-47$ \\
\hline TK2 & 0.615291641 & 0.702921916 & 0.192094042 & $1.71 E-15$ & $2.52 \mathrm{E}-13$ & -0.365352213 & $3.94 \mathrm{E}-16$ \\
\hline ZSCAN1 & 0.289768404 & 0.400355348 & 0.466380783 & $2.83 E-15$ & $4.19 E-13$ & -0.397488998 & $4.73 E-19$ \\
\hline ZNF677 & 0.220497196 & 0.315626597 & 0.517458471 & $2.86 \mathrm{E}-15$ & $4.23 \mathrm{E}-13$ & -0.527352048 & $1.21 \mathrm{E}-34$ \\
\hline ZNF582 & 0.130372053 & 0.239679107 & 0.878469505 & $5.74 \mathrm{E}-15$ & $8.49 E-13$ & -0.558968642 & $1.43 E-39$ \\
\hline DAPP1 & 0.510432574 & 0.394016678 & -0.373463704 & $1.29 E-14$ & $1.91 \mathrm{E}-12$ & -0.490584559 & $1.57 \mathrm{E}-29$ \\
\hline SRPX2 & 0.600591335 & 0.480798168 & -0.32095226 & $1.42 \mathrm{E}-14$ & $2.10 E-12$ & -0.383430149 & $9.83 E-18$ \\
\hline CCDC181 & 0.283605585 & 0.41823899 & 0.560441617 & $3.23 E-14$ & $4.78 \mathrm{E}-12$ & -0.319044754 & $1.84 \mathrm{E}-12$ \\
\hline SULT4A1 & 0.24652482 & 0.348099193 & 0.497765567 & $7.69 \mathrm{E}-14$ & $1.14 \mathrm{E}-11$ & -0.358208198 & $1.59 \mathrm{E}-15$ \\
\hline LRRC4 & 0.321370351 & 0.418618502 & 0.38139924 & $1.26 \mathrm{E}-13$ & $1.87 \mathrm{E}-11$ & -0.421045183 & $2.10 \mathrm{E}-21$ \\
\hline ZSCAN23 & 0.12251013 & 0.209336095 & 0.772920046 & $1.57 \mathrm{E}-13$ & $2.32 \mathrm{E}-11$ & -0.362584137 & $6.80 E-16$ \\
\hline F2RL1 & 0.242790645 & 0.208656331 & -0.218584138 & $1.74 \mathrm{E}-13$ & $2.57 \mathrm{E}-11$ & -0.35941342 & $1.26 \mathrm{E}-15$ \\
\hline ZNF334 & 0.17466699 & 0.256829933 & 0.556206371 & $2.31 E-13$ & $3.43 E-11$ & -0.459451082 & $1.16 \mathrm{E}-25$ \\
\hline ZNF471 & 0.130738051 & 0.279080546 & 1.094002465 & $5.46 \mathrm{E}-13$ & $8.07 E-11$ & -0.548011494 & $8.37 E-38$ \\
\hline HOXB2 & 0.34354942 & 0.513088034 & 0.578688733 & $6.70 \mathrm{E}-13$ & $9.91 \mathrm{E}-11$ & -0.491155695 & $1.32 \mathrm{E}-29$ \\
\hline PRR19 & 0.666407262 & 0.728756031 & 0.129031796 & $9.23 \mathrm{E}-13$ & $1.37 \mathrm{E}-10$ & -0.420836129 & $2.20 E-21$ \\
\hline AGR2 & 0.669953934 & 0.554274136 & -0.273462209 & $1.68 \mathrm{E}-12$ & $2.49 \mathrm{E}-10$ & -0.51205684 & $1.93 \mathrm{E}-32$ \\
\hline NQO1 & 0.702158099 & 0.525979398 & -0.416789616 & $2.08 \mathrm{E}-12$ & $3.08 \mathrm{E}-10$ & -0.425444078 & $7.26 \mathrm{E}-22$ \\
\hline GIPC2 & 0.179310415 & 0.281572165 & 0.651045433 & $3.52 E-12$ & $5.21 \mathrm{E}-10$ & -0.36721046 & $2.73 E-16$ \\
\hline OXT & 0.553265288 & 0.656785573 & 0.247451026 & $4.61 E-12$ & $6.83 E-10$ & -0.519344744 & $1.77 E-33$ \\
\hline B3GALT2 & 0.534256964 & 0.658626901 & 0.301927631 & $6.78 \mathrm{E}-12$ & $1.00 \mathrm{E}-09$ & -0.477778193 & $6.83 E-28$ \\
\hline EFS & 0.197613625 & 0.297157242 & 0.588544115 & $1.42 \mathrm{E}-11$ & $2.10 E-09$ & -0.391422631 & $1.78 \mathrm{E}-18$ \\
\hline RAB34 & 0.295528869 & 0.254270265 & -0.21693631 & $2.05 E-11$ & $3.03 E-09$ & -0.424411453 & $9.32 E-22$ \\
\hline ACTRT3 & 0.391186063 & 0.353188058 & -0.147418408 & $5.54 \mathrm{E}-11$ & $8.21 \mathrm{E}-09$ & -0.329154572 & $3.27 \mathrm{E}-13$ \\
\hline CLDN8 & 0.727830255 & 0.618464903 & -0.234910297 & $9.70 E-11$ & $1.44 \mathrm{E}-08$ & -0.328690081 & $3.55 E-13$ \\
\hline
\end{tabular}


Table 1 (continued)

\begin{tabular}{|c|c|c|c|c|c|c|c|}
\hline mRNA & Normal mean & Tumor mean & $\log \mathrm{FC}$ & $P$ Value & Adjusted-P & Cor & Cor P-value \\
\hline AQP1 & 0.366569984 & 0.501482299 & 0.452110121 & $2.34 \mathrm{E}-10$ & $3.46 \mathrm{E}-08$ & -0.597245937 & $2.74 \mathrm{E}-46$ \\
\hline SP8 & 0.202841356 & 0.297916967 & 0.554558466 & $2.69 \mathrm{E}-10$ & $3.98 \mathrm{E}-08$ & -0.317009628 & $2.58 \mathrm{E}-12$ \\
\hline HORMAD2 & 0.350476203 & 0.461146819 & 0.395909658 & $3.14 \mathrm{E}-10$ & $4.65 \mathrm{E}-08$ & -0.457907737 & $1.76 \mathrm{E}-25$ \\
\hline GALM & 0.255948625 & 0.226747119 & -0.174770041 & $6.86 \mathrm{E}-10$ & $1.02 \mathrm{E}-07$ & -0.356239606 & $2.33 \mathrm{E}-15$ \\
\hline RABGGTB & 0.47835678 & 0.385164319 & -0.312612985 & $6.89 \mathrm{E}-10$ & $1.02 \mathrm{E}-07$ & -0.3330019 & $1.67 \mathrm{E}-13$ \\
\hline KCNE3 & 0.256671142 & 0.314316199 & 0.292295525 & $7.52 \mathrm{E}-10$ & $1.11 \mathrm{E}-07$ & -0.350037722 & $7.53 \mathrm{E}-15$ \\
\hline ZNF879 & 0.147629821 & 0.2000367 & 0.438280535 & $1.01 E-09$ & $1.50 \mathrm{E}-07$ & -0.453856587 & $5.23 \mathrm{E}-25$ \\
\hline ZNF257 & 0.157589016 & 0.245609973 & 0.640202155 & $1.28 \mathrm{E}-09$ & $1.89 \mathrm{E}-07$ & -0.359120932 & $1.34 \mathrm{E}-15$ \\
\hline ZNF382 & 0.101492 & 0.295488981 & 1.541738316 & 1.35E-09 & $1.99 \mathrm{E}-07$ & -0.391566521 & $1.73 \mathrm{E}-18$ \\
\hline GSTM1 & 0.156396431 & 0.253910031 & 0.699109797 & $2.76 \mathrm{E}-09$ & $4.08 \mathrm{E}-07$ & -0.563212162 & $2.84 \mathrm{E}-40$ \\
\hline PLAU & 0.62150196 & 0.702145935 & 0.176011973 & 4.00E-09 & $5.92 \mathrm{E}-07$ & -0.570934425 & $1.41 \mathrm{E}-41$ \\
\hline PIGR & 0.667952501 & 0.708575582 & 0.085176236 & $5.52 \mathrm{E}-09$ & $8.16 \mathrm{E}-07$ & -0.658618149 & $3.68 \mathrm{E}-59$ \\
\hline CFTR & 0.282943087 & 0.394972666 & 0.481240926 & $9.95 \mathrm{E}-09$ & 1.47E-06 & -0.42150843 & $1.88 \mathrm{E}-21$ \\
\hline SPDYC & 0.704147468 & 0.724837107 & 0.041779213 & $1.76 \mathrm{E}-08$ & $2.60 \mathrm{E}-06$ & -0.47588325 & $1.18 \mathrm{E}-27$ \\
\hline ZNF418 & 0.242511045 & 0.347906619 & 0.520649675 & $2.19 \mathrm{E}-08$ & $3.23 \mathrm{E}-06$ & -0.60435923 & $1.23 \mathrm{E}-47$ \\
\hline KLHDC9 & 0.218223326 & 0.21602453 & -0.014610182 & $2.63 \mathrm{E}-08$ & $3.90 \mathrm{E}-06$ & -0.324984031 & $6.72 \mathrm{E}-13$ \\
\hline ZNF69 & 0.117564379 & 0.142619404 & 0.278719274 & $2.66 \mathrm{E}-08$ & $3.94 \mathrm{E}-06$ & -0.321104504 & $1.30 \mathrm{E}-12$ \\
\hline FAM84A & 0.212175332 & 0.283041565 & 0.415757 & $3.53 \mathrm{E}-08$ & $5.23 \mathrm{E}-06$ & -0.335916441 & $9.96 \mathrm{E}-14$ \\
\hline PPP1R14D & 0.554947827 & 0.482097369 & -0.203027589 & $6.64 \mathrm{E}-08$ & $9.82 \mathrm{E}-06$ & -0.560710402 & $7.40 \mathrm{E}-40$ \\
\hline TCP11 & 0.624104627 & 0.659912943 & 0.080487807 & $7.18 \mathrm{E}-08$ & $1.06 \mathrm{E}-05$ & -0.651746879 & $1.43 \mathrm{E}-57$ \\
\hline ZNF300 & 0.328409005 & 0.415250076 & 0.338486746 & $9.38 \mathrm{E}-08$ & $1.39 \mathrm{E}-05$ & -0.472110183 & $3.46 \mathrm{E}-27$ \\
\hline MPV17L & 0.092385716 & 0.163253978 & 0.821376431 & $1.86 \mathrm{E}-07$ & $2.75 E-05$ & -0.441792534 & $1.23 \mathrm{E}-23$ \\
\hline KRT20 & 0.790374237 & 0.804070021 & 0.02478522 & $2.92 \mathrm{E}-07$ & 4.33E-05 & -0.571800235 & $1.00 \mathrm{E}-41$ \\
\hline GKN2 & 0.599299248 & 0.671212935 & 0.163493955 & $4.56 \mathrm{E}-07$ & $6.76 \mathrm{E}-05$ & -0.340697654 & $4.22 \mathrm{E}-14$ \\
\hline ZNF502 & 0.329208879 & 0.402697069 & 0.290691725 & $6.68 \mathrm{E}-07$ & $9.88 \mathrm{E}-05$ & -0.663271171 & $2.91 \mathrm{E}-60$ \\
\hline C17orf98 & 0.545496557 & 0.602566194 & 0.143549644 & $1.03 \mathrm{E}-06$ & 0.000151843 & -0.529865333 & $5.12 \mathrm{E}-35$ \\
\hline ZNF880 & 0.140875018 & 0.238786926 & 0.76130805 & $1.04 \mathrm{E}-06$ & 0.000154315 & -0.560715099 & $7.38 \mathrm{E}-40$ \\
\hline ZNF701 & 0.240700225 & 0.290476188 & 0.271182411 & $1.55 \mathrm{E}-06$ & 0.000229592 & -0.408643207 & $3.83 \mathrm{E}-20$ \\
\hline NROB1 & 0.283614274 & 0.392651776 & 0.469320279 & $1.59 \mathrm{E}-06$ & 0.000235507 & -0.320709703 & $1.39 \mathrm{E}-12$ \\
\hline ZNF43 & 0.067179039 & 0.115788942 & 0.78541442 & $1.79 \mathrm{E}-06$ & 0.000265629 & -0.375124186 & $5.52 \mathrm{E}-17$ \\
\hline HCAR1 & 0.43400231 & 0.376162376 & -0.206347167 & $1.93 \mathrm{E}-06$ & 0.000285658 & -0.401199574 & $2.07 \mathrm{E}-19$ \\
\hline IRX2 & 0.289887257 & 0.40281496 & 0.474625351 & $3.59 \mathrm{E}-06$ & 0.000530859 & -0.539421825 & $1.83 \mathrm{E}-36$ \\
\hline TMEM63A & 0.188744901 & 0.177446694 & -0.089051973 & 4.10E-06 & 0.000607535 & -0.345096982 & $1.89 \mathrm{E}-14$ \\
\hline ITPRIPL1 & 0.294502802 & 0.374069204 & 0.345023839 & $4.14 \mathrm{E}-06$ & 0.000613146 & -0.44960488 & $1.61 \mathrm{E}-24$ \\
\hline LYZ & 0.699231698 & 0.733682794 & 0.069385864 & 4.77E-06 & 0.000705417 & -0.424840466 & $8.40 \mathrm{E}-22$ \\
\hline IFNLR1 & 0.246226199 & 0.232227751 & -0.084443891 & $9.60 \mathrm{E}-06$ & 0.001421224 & -0.420673159 & $2.29 \mathrm{E}-21$ \\
\hline TUSC1 & 0.13659181 & 0.18296341 & 0.421684184 & $9.60 \mathrm{E}-06$ & 0.001421229 & -0.395587597 & $7.19 \mathrm{E}-19$ \\
\hline MAGEB2 & 0.842482835 & 0.77366049 & -0.122946694 & $1.08 \mathrm{E}-05$ & 0.001598591 & -0.352008819 & $5.20 \mathrm{E}-15$ \\
\hline BVES & 0.191406638 & 0.252664551 & 0.400582407 & $1.12 \mathrm{E}-05$ & 0.001655808 & -0.321449081 & $1.23 \mathrm{E}-12$ \\
\hline LRRIQ4 & 0.704379076 & 0.645150221 & -0.126716926 & $1.21 \mathrm{E}-05$ & 0.001791741 & -0.38912631 & $2.93 \mathrm{E}-18$ \\
\hline RASSF10 & 0.120420032 & 0.181039038 & 0.588225416 & $5.00 \mathrm{E}-05$ & 0.007400364 & -0.328252794 & $3.83 E-13$ \\
\hline PRICKLE4 & 0.605330662 & 0.686379771 & 0.181283603 & $8.15 \mathrm{E}-05$ & 0.012068682 & -0.318883347 & $1.89 \mathrm{E}-12$ \\
\hline SYCP2 & 0.665037997 & 0.675303689 & 0.022099668 & 0.000123074 & 0.018214969 & -0.655943521 & $1.55 \mathrm{E}-58$ \\
\hline WBP2NL & 0.524579367 & 0.489275744 & -0.1005133 & 0.000184004 & 0.027232614 & -0.343246032 & $2.65 \mathrm{E}-14$ \\
\hline BST2 & 0.422881206 & 0.380549863 & -0.152166944 & 0.000187292 & 0.027719241 & -0.589617095 & $7.07 \mathrm{E}-45$ \\
\hline PLSCR4 & 0.17571366 & 0.196664014 & 0.162506649 & 0.000241916 & 0.035803514 & -0.365149084 & $4.10 \mathrm{E}-16$ \\
\hline GBP4 & 0.149941894 & 0.137445221 & -0.125546784 & 0.000249246 & 0.036888372 & -0.316476516 & $2.82 \mathrm{E}-12$ \\
\hline RPL7A & 0.801995847 & 0.754500966 & -0.088072019 & 0.000275207 & 0.040730644 & -0.319271372 & 1.77E-12 \\
\hline ARHGDIB & 0.327607353 & 0.313354218 & -0.064173323 & 0.000282085 & 0.04174863 & -0.552243 & 1.77E-38 \\
\hline CYB5A & 0.127300153 & 0.141309476 & 0.150624055 & 0.000302943 & 0.044835593 & -0.371106098 & $1.25 \mathrm{E}-16$ \\
\hline
\end{tabular}


Table 2 Methylation-driven IncRNAs

\begin{tabular}{lllllllc}
\hline IncRNA & Normal mean & Tumor mean & logFC & P-value & Adjusted-P & Cor & Cor P-value \\
\hline HOTAIRM1 & 0.250463518 & 0.44338384 & 0.823955709 & $2.68 \mathrm{E}-19$ & $6.44 \mathrm{E}-18$ & -0.326878646 & $4.85 \mathrm{E}-13$ \\
HOXB-AS3 & 0.319686633 & 0.449195438 & 0.490684853 & $5.50 \mathrm{E}-18$ & $1.32 \mathrm{E}-16$ & -0.412913672 & $1.43 \mathrm{E}-20$ \\
HOXB-AS1 & 0.335041907 & 0.484121893 & 0.531028779 & $1.17 \mathrm{E}-17$ & $2.80 \mathrm{E}-16$ & -0.459143798 & $1.26 \mathrm{E}-25$ \\
AF186192.1 & 0.153517115 & 0.289865274 & 0.916983002 & $1.36 \mathrm{E}-16$ & $3.26 \mathrm{E}-15$ & -0.432033057 & $1.44 \mathrm{E}-22$ \\
WASIR2 & 0.67568 & 0.534227796 & -0.33888511 & $3.03 \mathrm{E}-16$ & $7.26 \mathrm{E}-15$ & -0.38041164 & $1.85 \mathrm{E}-17$ \\
HOXC-AS3 & 0.180457648 & 0.304425709 & 0.754429909 & $3.10 \mathrm{E}-15$ & $7.45 \mathrm{E}-14$ & -0.33684433 & $8.44 \mathrm{E}-14$ \\
LINC01354 & 0.507119955 & 0.656977352 & 0.373516594 & $2.20 \mathrm{E}-14$ & $5.28 \mathrm{E}-13$ & -0.491825621 & $1.08 \mathrm{E}-29$ \\
BARX1-AS1 & 0.469474928 & 0.571905661 & 0.284729072 & $1.61 \mathrm{E}-13$ & $3.87 \mathrm{E}-12$ & -0.485400012 & $7.36 \mathrm{E}-29$ \\
AC005498.3 & 0.077393911 & 0.150762843 & 0.96198899 & $9.66 \mathrm{E}-11$ & $2.32 \mathrm{E}-09$ & -0.347615295 & $1.18 \mathrm{E}-14$ \\
AC147651.4 & 0.545827883 & 0.59134957 & 0.115565122 & $9.66 \mathrm{E}-11$ & $2.32 \mathrm{E}-09$ & -0.35424262 & $3.41 \mathrm{E}-15$ \\
LINC00676 & 0.65637148 & 0.770329464 & 0.230963053 & $2.88 \mathrm{E}-10$ & $6.92 \mathrm{E}-09$ & -0.652305415 & $1.07 \mathrm{E}-57$ \\
LINC01460 & 0.232370826 & 0.19315723 & -0.266653276 & $4.57 \mathrm{E}-09$ & $1.10 \mathrm{E}-07$ & -0.364997272 & $4.23 \mathrm{E}-16$ \\
AC023824.1 & 0.646522945 & 0.703429803 & 0.121704887 & $7.06 \mathrm{E}-09$ & $1.69 \mathrm{E}-07$ & -0.365841735 & $3.58 \mathrm{E}-16$ \\
LINC01535 & 0.227839948 & 0.292001828 & 0.357956684 & $4.99 \mathrm{E}-07$ & $1.20 \mathrm{E}-05$ & -0.371976592 & $1.05 \mathrm{E}-16$ \\
LINC00506 & 0.141670097 & 0.203560361 & 0.522921383 & $3.03 \mathrm{E}-05$ & 0.000726506 & -0.330461443 & $2.61 \mathrm{E}-13$ \\
TUSC8 & 0.806078873 & 0.749074143 & -0.105812488 & $9.91 \mathrm{E}-05$ & 0.002378923 & -0.713080072 & $2.02 \mathrm{E}-73$ \\
LINC00847 & 0.820916916 & 0.824558907 & 0.006386348 & 0.001130654 & 0.027135699 & -0.35046797 & $6.95 \mathrm{E}-15$ \\
\hline
\end{tabular}

\section{Combined methylation and gene expression survival analysis in LUAD}

The combined Kaplan-Meier curve analysis revealed that the combination of methylation and expression of lncRNAs AC023824.1, AF186192.1, LINC01354 and WASIR2 had a conspicuous correlation with the prognosis of LUAD patients (Fig. 6a-d). The hypermethylation and low-expression survival rate of AC023824.1 was high, while the hypermethylation and low-expression survival rate of AF186192.1, LINC01354 and WASIR2 were low. The combined Kaplan-Meier curve analysis showed that the combination of methylation and mRNA expression of mRNAs CCDC181, EFS, F2RL1, GKN2, ITPRIPL1, KLHDC9, MPV17L, and S1PR1 were associated with overall survival of LUAD $(P<0.05)$ (Fig. $6 \mathrm{e}-1)$. The hypermethylation and low-expression survival rate of F2RL1 was high. However, the hypermethylation and low-expression survival rates of EFS, CCDC181, GKN2, ITPRIPL1, KLHDC9, MPV17L, and S1PR1 were low (Fig. 6).

\section{Discussion}

In recent years, with the increasing numbers of advanced diagnoses and poor prognoses in lung adenocarcinoma, it is pivotal to find more effective prognostic biomarkers to predict survival in LUAD. LncRNA-related studies have attracted the attention of various cancer fields. Accumulating studies show that cancer-related lncRNAs may serve as diagnostic or predictive biomarkers of cancer and have a significant effect on the therapeutic treatment of cancer [27]. Emerging evidence shows that studies on the molecular mechanisms and prognostic biomarkers of LUAD associated with methylation-driven lncRNA and mRNA are still lacking.

In recent years, epigenetic alterations in DNA methylation, noncoding RNA expression, chromatin modeling and post-transcriptional regulators have been found to play significant roles in the regulation and development of lung cancer pathogenesis [28-32]. Some studies have shown that epigenetic changes in DNA methylation cause changes in the expression of lncRNA, which might provide a novel insight to explore new biomarkers for predicting the prognosis of human cancer [33-36]. For instance, analysis of microarray data on gene expression and methylation showed that the expressions of lncRNAs LOC146880 and ENST00000439577 were regulated by DNA methylation, which might provide a new horizon to predict the diagnosis and prognosis of NSCLC [37]. Lu et al. indicated that MEG3 is significantly downregulated in NSCLC

(See figure on next page.)

Fig. 1 Identification of top hypermethylated and hypomethylated mRNAs and IncRNAs in LUAD. a A flow diagram of the exploration of methylation-driven mRNA and IncRNA in LUAD. b-e The methylation degree when comparing cancer patients to normal patients in LUAD. The red curve indicates the methylation degree from the cancer group, the green curve indicates the methylation degree from the normal group, and the black line above the figure is the distribution of methylation levels in normal patients. $\mathbf{f}-\mathbf{i}$ The correlation between methylation and gene expression in methylation-driven mRNAs and IncRNAs 
a
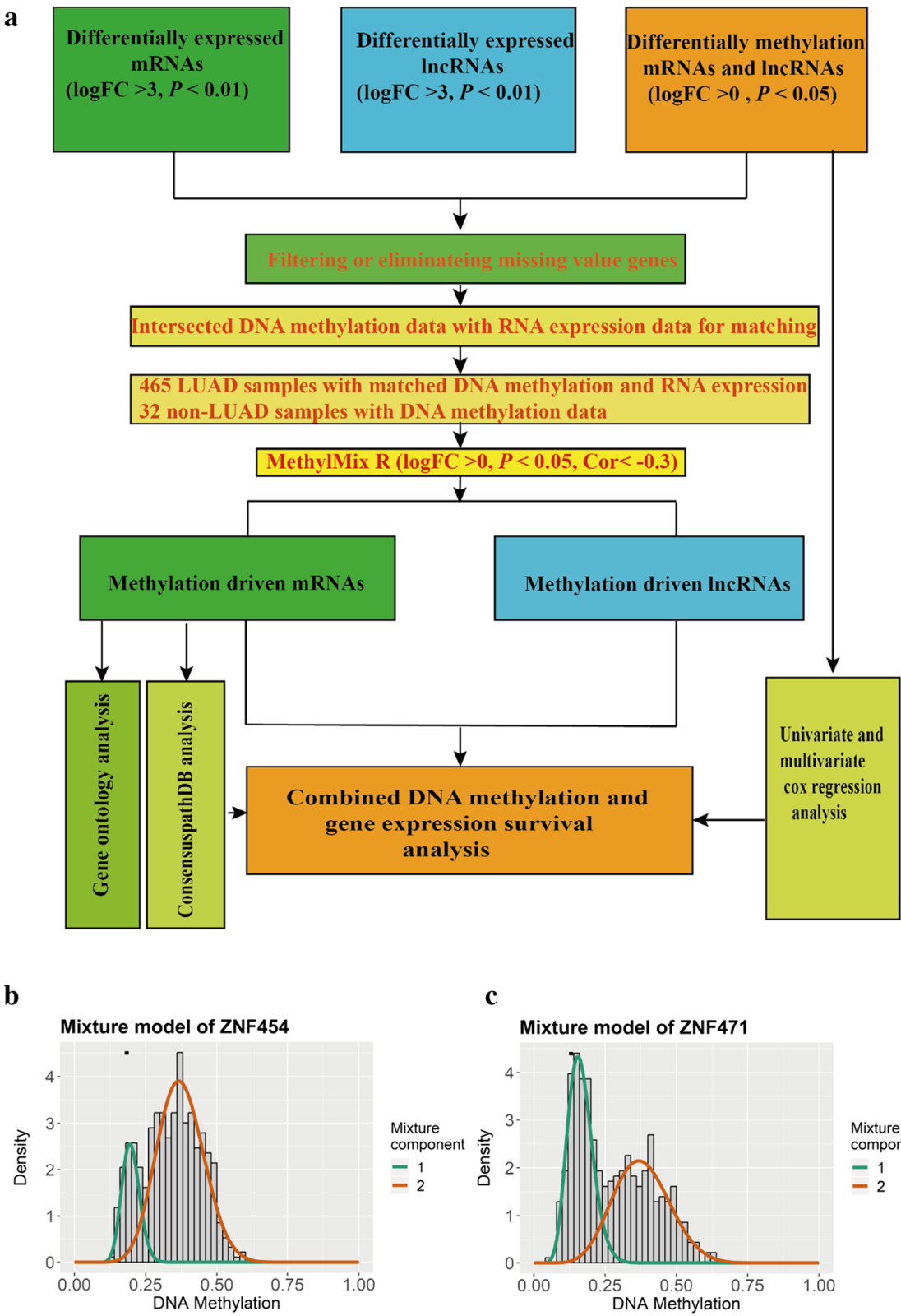

d

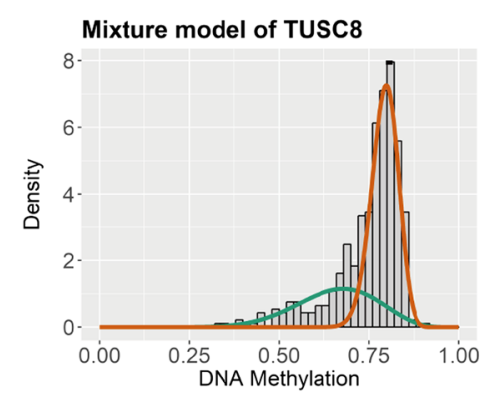

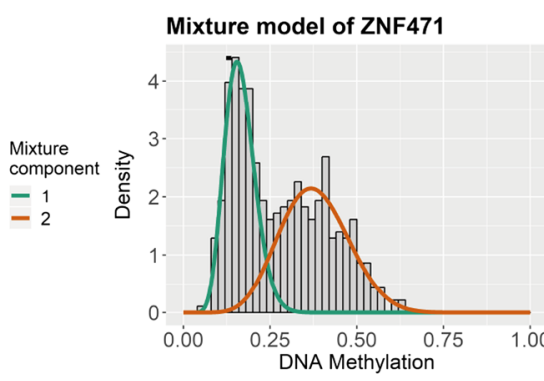

e

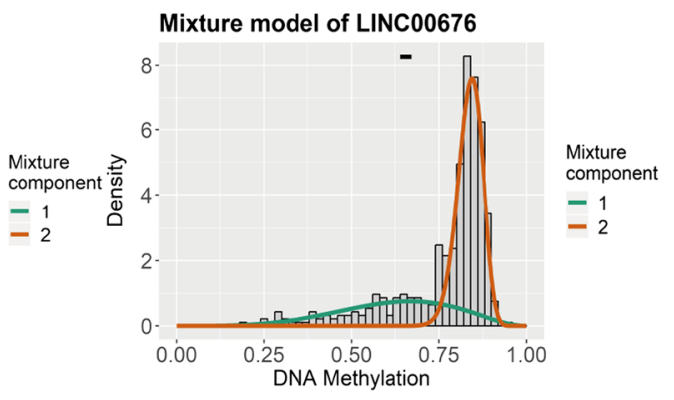

f

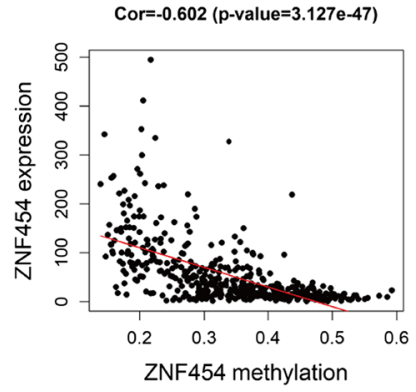

g

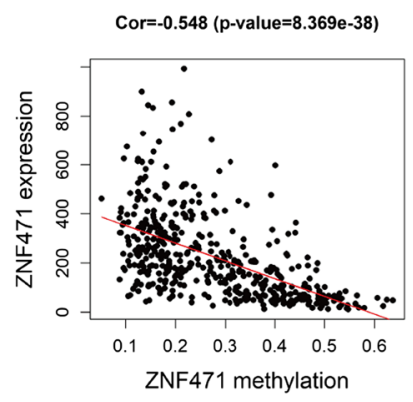

h

Cor $=-\mathbf{0 . 7 1 3}(p-$ value $=2.023 e-73)$

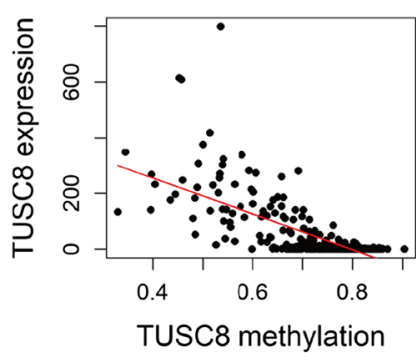

i

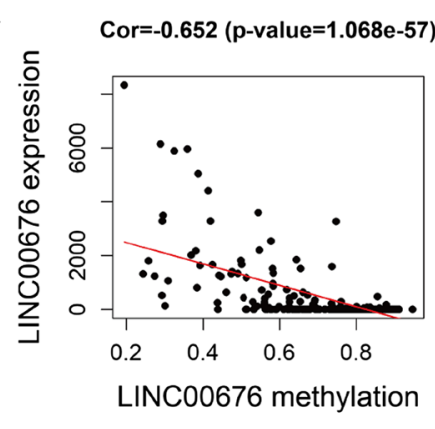




\section{a}

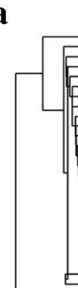

Type
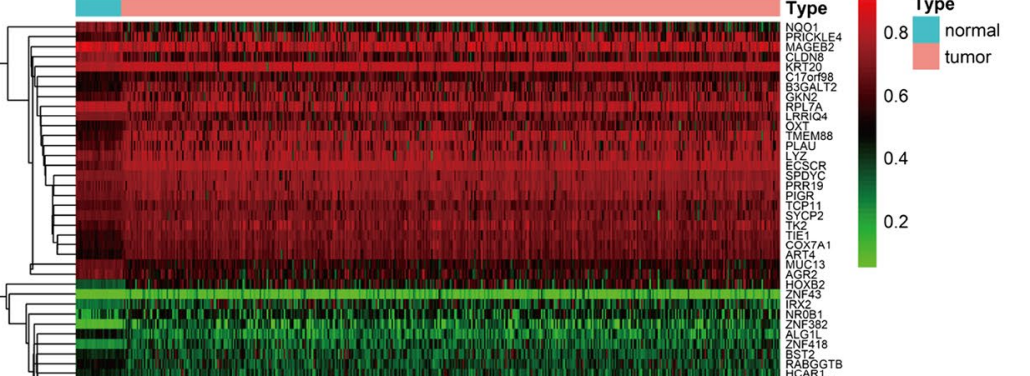

Type

0.8 normal

0.6

0.4

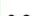
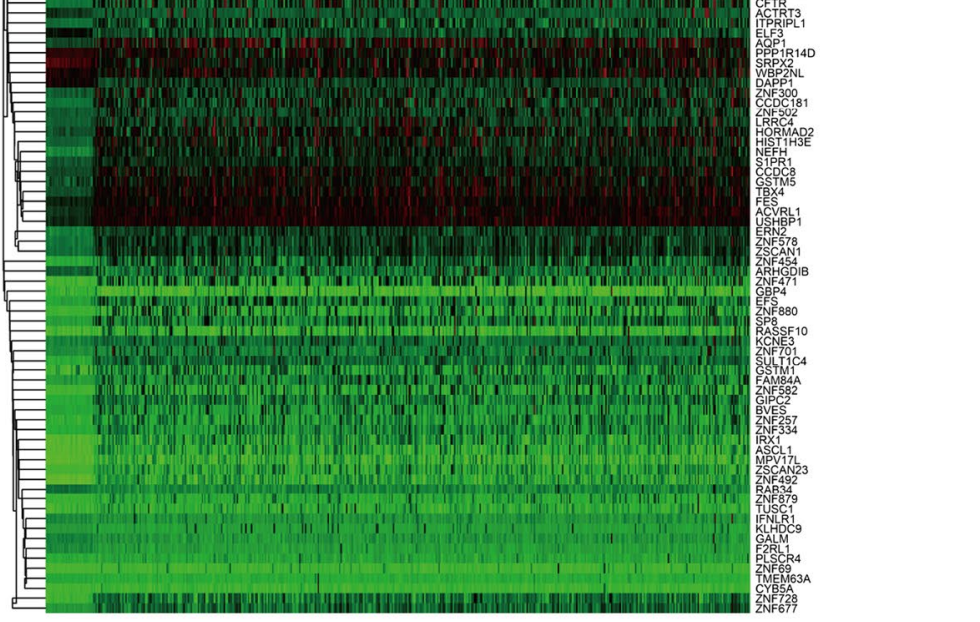

b

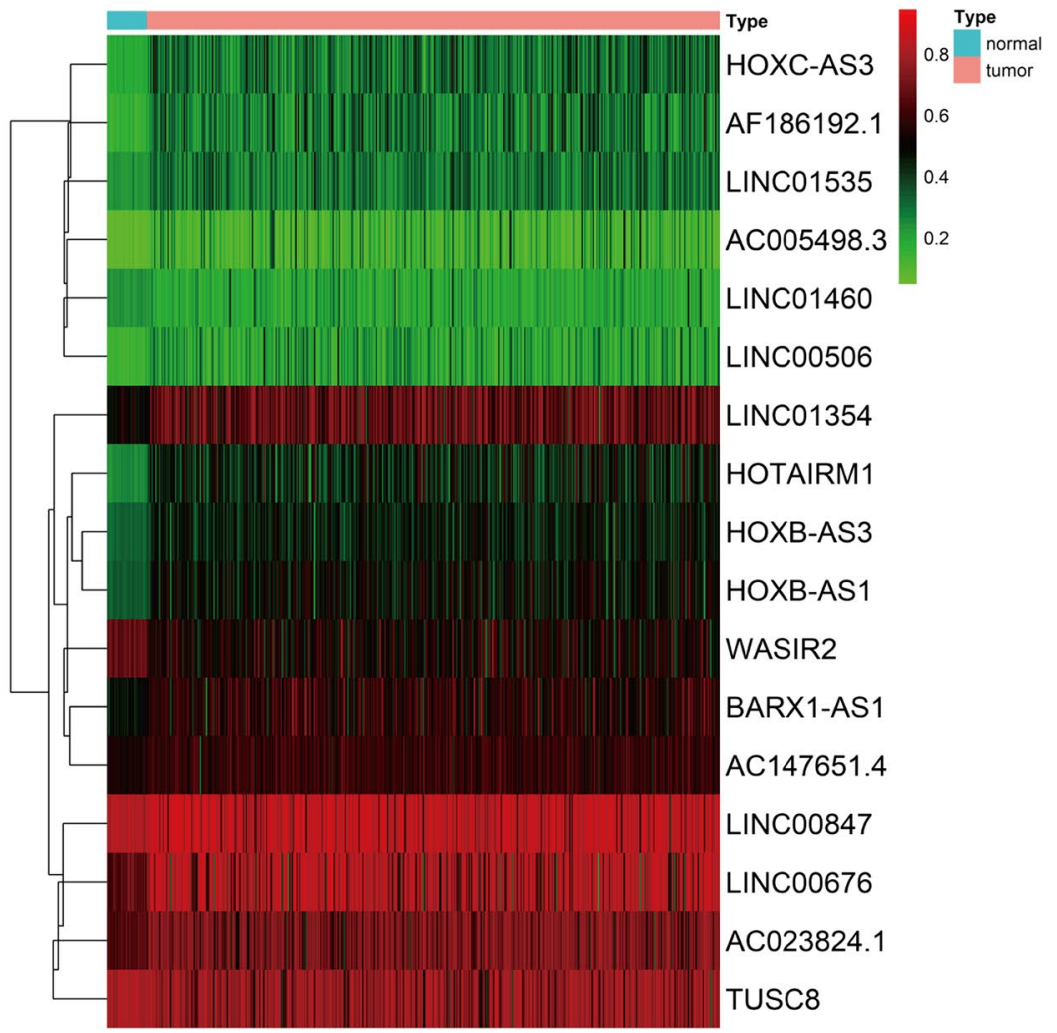

Fig. 2 Heat map of methylation-driven mRNAs and IncRNAs in LUAD. a The hierarchical clustering heat map of LUAD-specific methylation-driven mRNAs. b The hierarchical clustering heat map of LUAD-specific methylation-driven IncRNAs. In the figure, red represents highly methylated genes and green represents low methylated genes between LUAD and adjacent tissues 
a

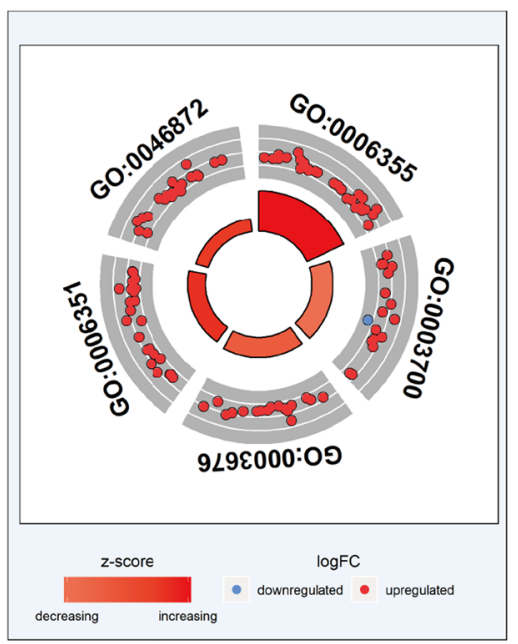

b

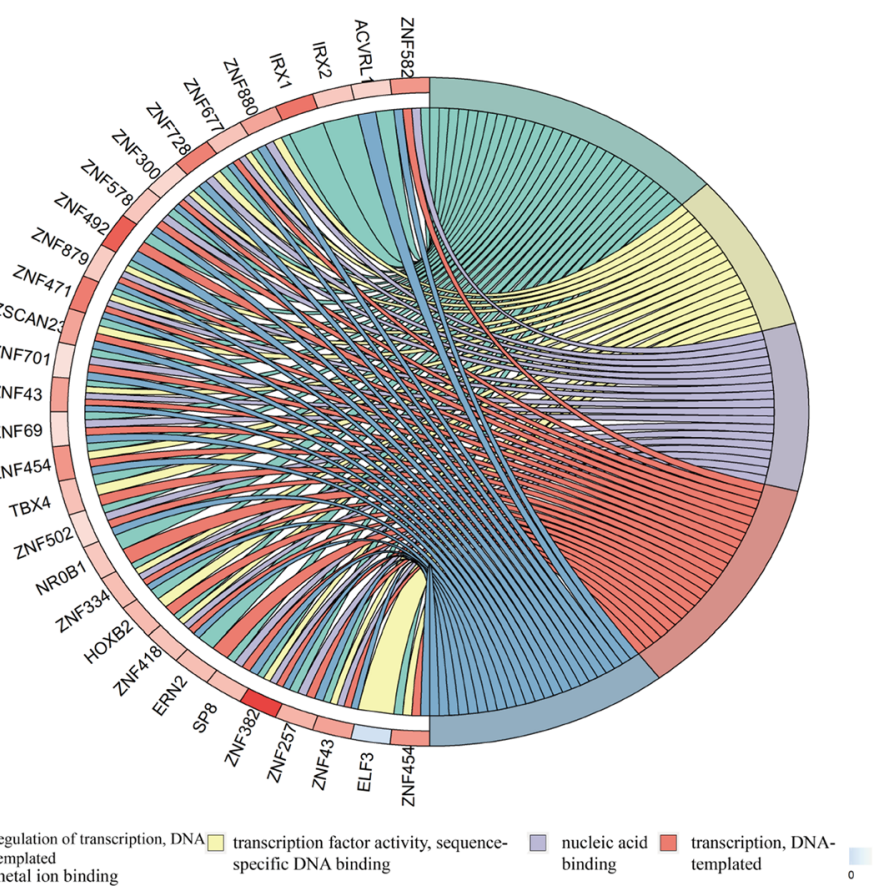

c

\begin{tabular}{|l|l|l|}
\hline Category & ID & Term \\
\hline BP & GO:0006355 & regulation of transcription, DNA-templated \\
\hline MF & GO:0003700 & transcription factor activity, sequence-specific DNA binding \\
\hline MF & GO:0003676 & nucleic acid binding \\
\hline BP & GO:0006351 & transcription, DNA-templated \\
\hline MF & GO:0046872 & metal ion binding \\
\hline
\end{tabular}

Fig. 3 Functional enrichment analysis of methylation-driven mRNAs in LUAD. a The outer circle represents the expression (logFC) of methylation-driven mRNAs in each enriched GO (gene ontology) term: red dots on each GO term indicate upregulated methylation-driven mRNAs and blue dots indicate downregulated methylation-driven mRNAs. The inner circle indicates the significance of GO terms (log10-adjusted $P$ values). b The circle indicates the correlation between the top 30 methylation-driven mRNAs and their gene ontology terms. c The distribution of the methylation-driven mRNAs in significant GO terms

tissues that could be affected by DNA methylation [38]. Previous studies have shown that survival-associated, methylation-driven lncRNAs might serve as novel prognostic biomarkers for predicting the prognosis of LUAD.

Recent studies have shown that the roles of IncRNA in tumorigenesis and metastasis can indicate that lncRNA may function as a novel biomarker for the diagnosis and prognosis of cancer [39-44]. LncRNA TUBA4B has been reported to serve as a new predictor for prognosis and modulate cell viability in non-small-cell lung cancer [45]. lncRNA AFAP1-AS1 may act as an oncogenic to facilitate the migration of non-small-cell lung cancer (NSCLC) [16]. Long noncoding RNA ANRIL acts as an oncogene by silencing KLF2 and P21 expression to promote the development of NSCLC [46]. LncRNA PANDAR acts as a cancer suppressor gene by regulating $\mathrm{Bcl}-2$ to affect cell apoptosis in NSCLC [47].
In the present study, we retrieved methylation and lncRNA and mRNA expression from the TCGA database by using bioinformatics analysis and obtained methylation-driven lncRNAs and mRNAs to predict the prognosis of LUAD. First, we obtained differentially expressed methylation and lncRNA and mRNA using the MethylMix R package to obtain methylation-driven lncRNA and mRNA. Functional enrichment analysis was performed to analyze the methylation-driven mRNA to identify its biological functions in the regulation and development of LUAD. Furthermore, univariate and multivariate Cox regressions were performed to construct a predictive model for predicting the prognosis of LUAD. Finally, a combined methylation and lncRNA expression survival analysis was carried out, which might provide novel insight to predict the diagnosis and prognosis of LUAD. 


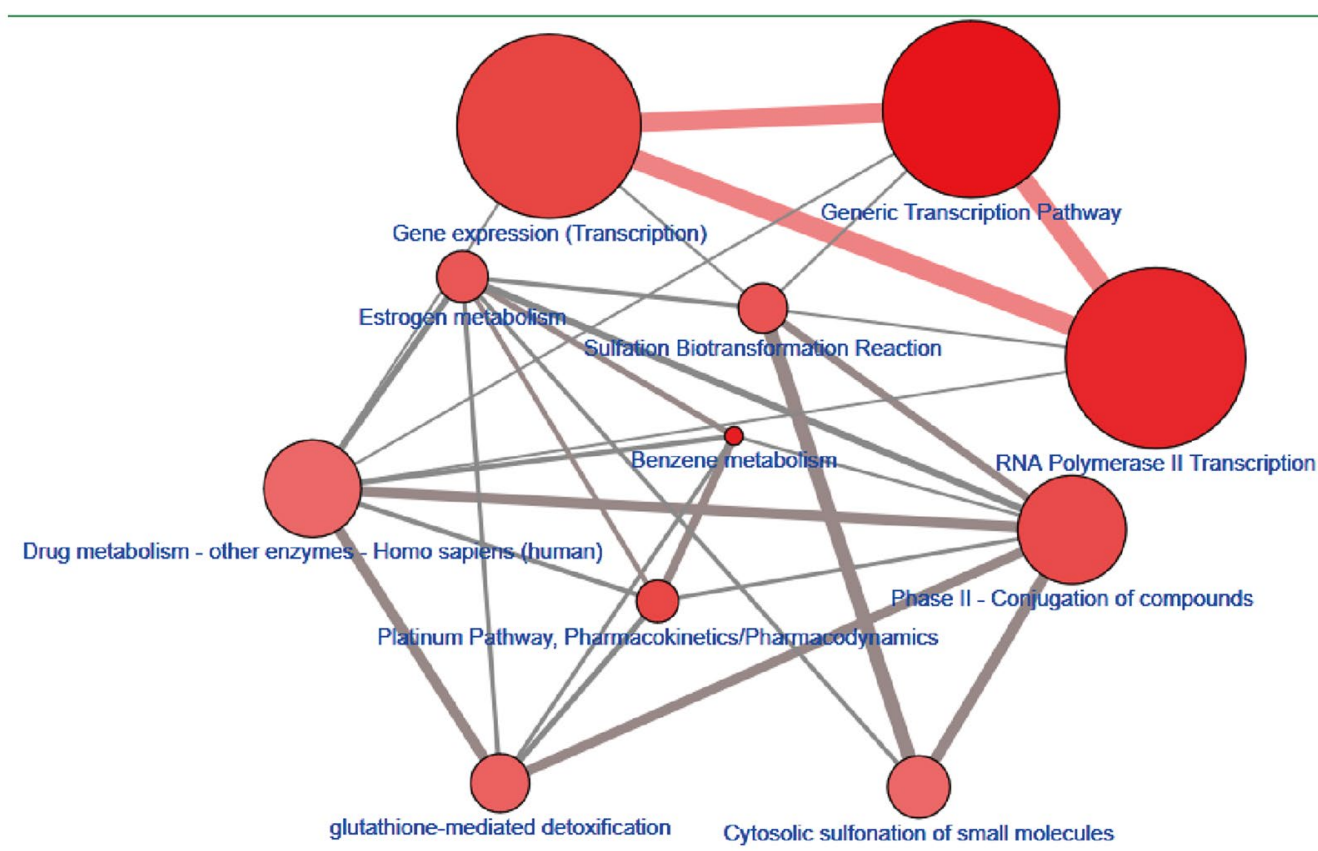

Node label color
The node label color
denotes the type of
the gene sets:
neighborhood-based set
manually curated pathway
Gene Ontology category
protein complex
protein complex

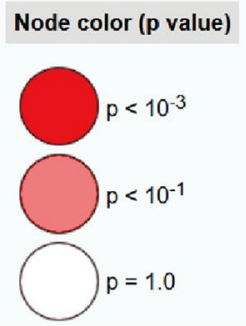

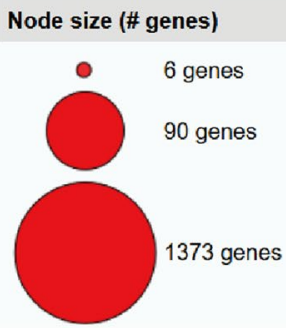

Edge width (\% shared genes)

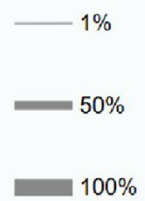

Edge color (genes from input)

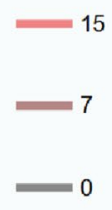

Fig. 4 Pathway analysis of methylation-driven mRNAs in LUAD. The red circles indicate the number of methylation-driven mRNAs on each pathway. The line between the two red circles represents the ratio of methylation-driven mRNAs present in the common genes of the two pathways; the thicker the line, the more common methylation-driven mRNAs are represented

Table 3 Pathway analysis

\begin{tabular}{llrrr}
\hline ID & Pathway & Count & P-value & q-value \\
\hline R-HSA-212436 & Generic transcription pathway & 15 & 0.000169248 & 0.01031453 \\
WP3891 & Benzene metabolism & 2 & 0.000338181 & 0.01031453 \\
R-HSA-73857 & RNA polymerase II transcription & 15 & 0.000564162 & 0.011471298 \\
R-HSA-74160 & Gene expression (transcription) & 15 & 0.001668004 & 0.020896371 \\
PA150642262 & Platinum pathway, Pharmacokinetics/pharmacodynamics & 2 & 0.001720726 & 0.020896371 \\
R-HSA-156580 & Phase II-conjugation of compounds & 4 & 0.002055381 & 0.020896371 \\
WP692 & Sulfation biotransformation reaction & 2 & 0.002963269 & 0.025340686 \\
WP697 & Estrogen metabolism & 2 & 0.003323369 & 0.025340686 \\
PWY-4061 & Glutathione-mediated detoxification & 2 & 0.005884846 & 0.035982304 \\
R-HSA-156584 & Cytosolic sulfonation of small molecules & 2 & 0.006376838 & 0.035982304 \\
Path:hsa00983 & Drug metabolism-other enzymes_Homo sapiens (human) & 3 & 0.006488612 & 0.035982304 \\
\hline
\end{tabular}

In the present study, we combined methylation and lncRNA and mRNA expression data with survival analysis to identify 4 lncRNAs and 8 mRNAs that act as independent prognostic factors for predicting the diagnosis and prognosis of LUAD. LINC01354 acts as a ceRNA to predict the early diagnosis and prognosis of colorectal 
Table 4 Multivariate Cox regression analysis of 6 IncRNAs associated with overall survival in LUAD patients

\begin{tabular}{lcclcl}
\hline & coef & exp(coef) & se(coef) & z & P \\
\hline FOXE1 & 3.004 & 20.1665 & 1.018 & 2.95 & 0.0032 \\
HOXB13-AS1_2 & 1.0226 & 2.7804 & 0.5657 & 1.81 & 0.0706 \\
VMO1 & 1.054 & 2.869 & 0.5992 & 1.76 & 0.0786 \\
HIST1H3F & 1.005 & 2.7319 & 0.3872 & 2.6 & 0.0094 \\
AJ003147.8 & -3.0925 & 0.0454 & 0.6695 & -4.62 & $3.80 E-06$ \\
ASXL3 & 1.4791 & 4.3888 & 0.7969 & 1.86 & 0.0635 \\
\hline
\end{tabular}

cancer [48]. The combined survival analysis showed that the low expression of AC023824.1 with hypermethylation, compared to the high expression of AC023824.1 with hypomethylation, had a higher survival rate. $(P=0)$. The combined hypermethylation and low-expression survival rate of AF186192.1 was lower than the hypomethylation and high-expression survival rate of AF186192.1. $(P=0.01)$. The low expression and hypermethylation survival rate of LINC01354 was low. $(P=0.038)$. The high expression and hypomethylation survival rate of WASIR2 was high. The survival analysis showed that lncRNA AF186192.1, LINC01354 and WASIR2 might act as cancer suppressor genes regulated by DNA methylation to play significant roles in predicting the prognosis of LUAD. LncRNA AC023824.1 might act as an oncogene regulated by DNA methylation to have a pivotal effect on predicting the prognosis of LUAD. The survival rate of hypermethylation and low expression of CCDC181, EFS, GKN2, ITPRIPL1, KLHDC9, MPV17L, and S1PR1 were low. However, the hypermethylation and lowexpression of the survival rate of F2RL1 was high. F2RL1 might act as an oncogene for predicting the prognosis of LUAD. Previous studies have shown that CCDC181, KLHDC9, and S1PR1 act as methylation-driven genes to reveal prognostic biomarkers in LUAD [19]. GKN2 may contribute to the homeostasis of gastric epithelial cells by inhibiting GKN1 activity [49]. F2RL1 may act as novel acute myeloid leukemia subsets that are meaning

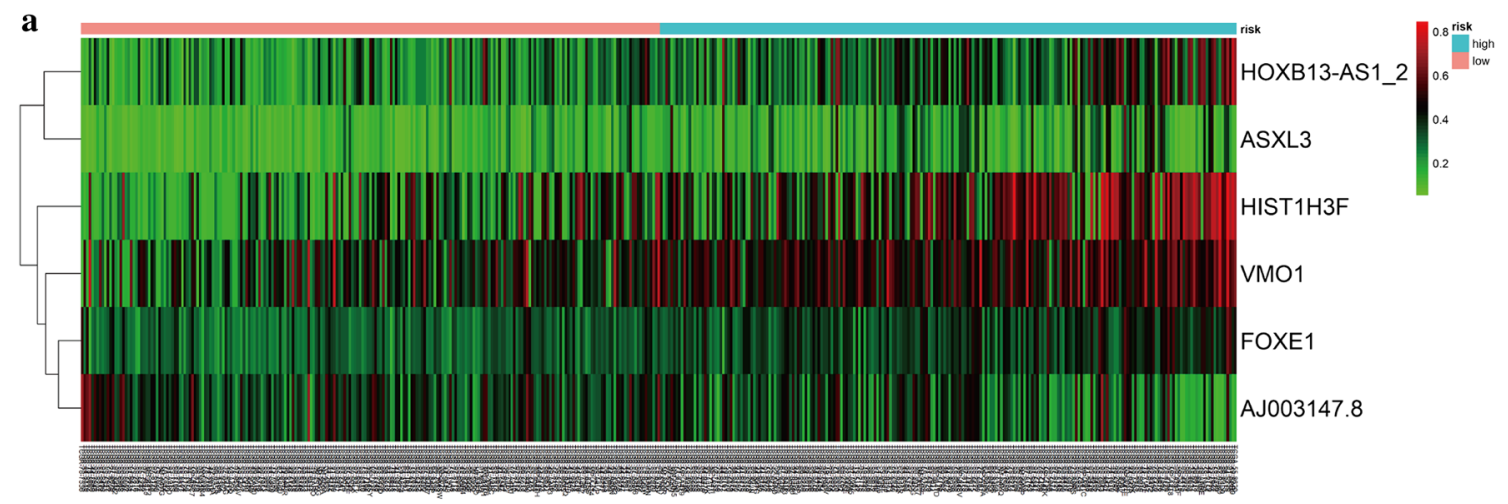

b survival curve $(p=0)$

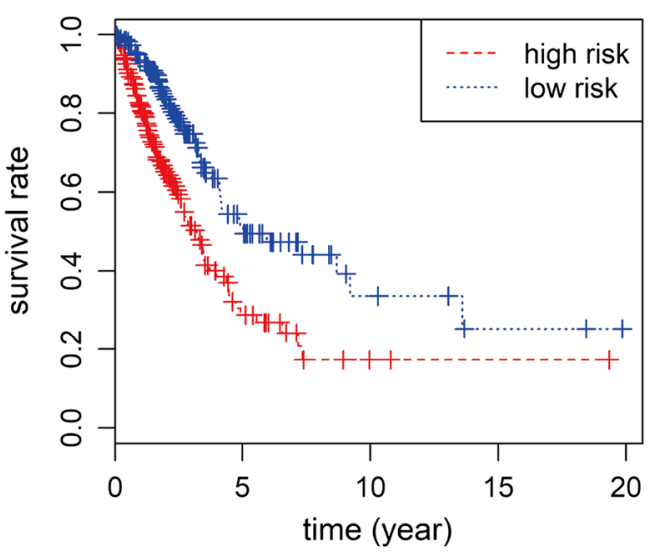

c

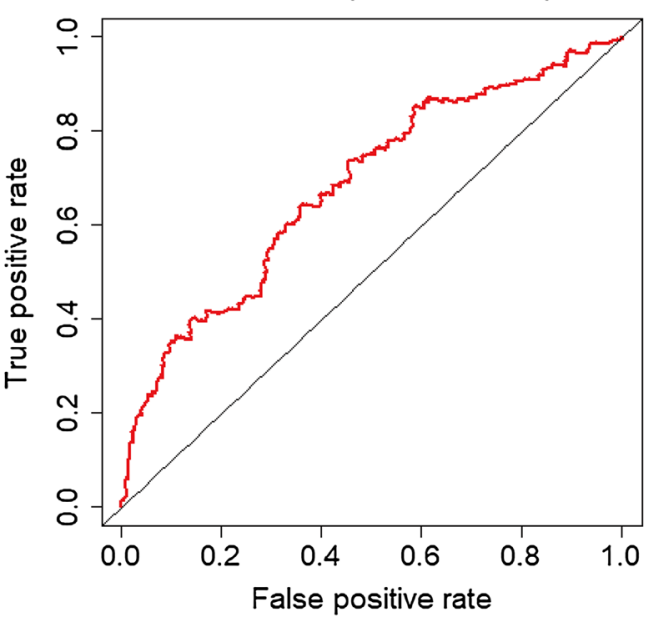

Fig. 5 Prognostic value of 6-methylation IncRNAs in LUAD. a A risk heat map established from 6 IncRNAs from 449 LUAD patients. b Kaplan-Meier curve analysis for OS (overall survival) of LUAD patients using the 6 IncRNA signatures. $\mathbf{c}$ ROC curve analysis of the prognostic 6 -IncRNA signature 

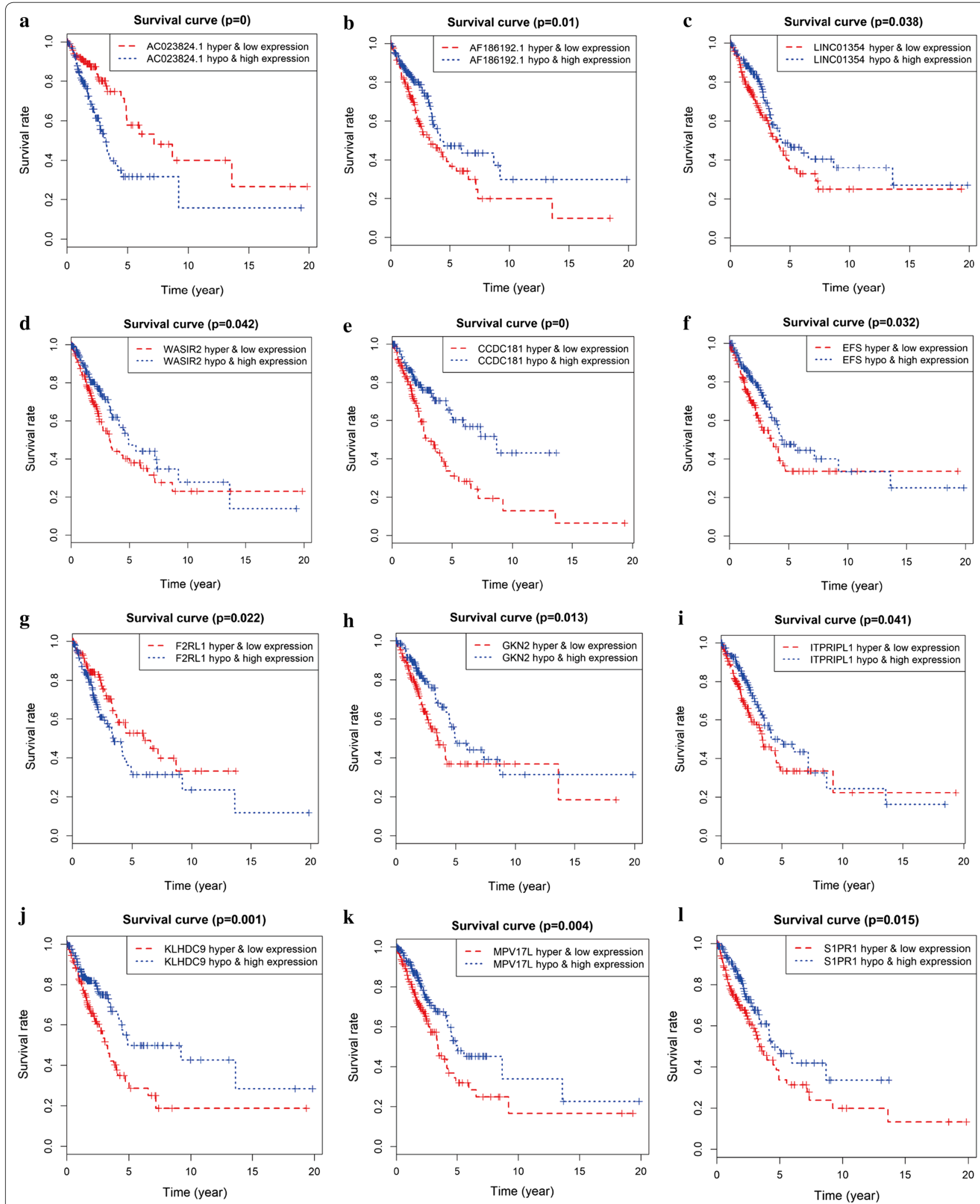

Fig. 6 The combined methylation and gene expression data survival analysis in LUAD. a-d Kaplan-Meier curve analysis of four IncRNAs in LUAD. e-I Kaplan-Meier curve analysis of eight mRNAs in LUAD 
for treatment guidance [50]. MPV17L acts as a unique interacting protein and regulator of $\mathrm{HtrA} 2$ protease, mediating antioxidant and antiapoptotic functions in mitochondria [51]. Compared with previous studies, our study first obtained differentially expressed mRNA and lncRNA using the edge R package and aberrant methylated genes using the limma $R$ package, and then we filtered low expression genes and intersected mRNA and lncRNA expression data with DNA methylation data to obtain methylation-driven genes by using the MethylMix $\mathrm{R}$ package. The MethylMix (https://bioconductor.riken .jp/packages/3.1/bioc/html/MethylMix.html) is an algorithm implemented to integrate DNA methylation with RNA expression to identify methylation-driven genes in cancers [52]. In summary, MethylMix provides a tool that contributes to the analysis of methylation-driven lncRNAs and mRNAs in cancer studies from TCGA $[17,18]$. However, the MethylMix focuses on identifying cis-regulatory effects of DNA methylation on gene expression and does not currently model trans-regulatory effects [18]. Further studies are needed to solve the multiple testing challenge on identifying trans-regulatory effects of DNA methylation on gene expression. Our study may provide a novel method for determining disease-specific prognostic biomarkers in LUAD and may play a significant role in predicting the diagnosis and prognosis of LUAD.

Our study subjects were retrieved from the TCGA database, which is a significant tool for analyzing prognostic biomarkers. It is not known whether our results are applicable to other groups. The predictive prognostic lncRNA and mRNA signature needs to be verified by molecular biologic experiments on clinical samples in future studies. Eventually, large-scale samples and experimental studies could validate the biological function of prognostic biomarkers in LUAD.

\section{Conclusion}

In conclusion, our study identified methylation-driven mRNA and lncRNA by using bioinformatics analysis from the TCGA database. A Cox predictive model was performed to identify independent prognostic factors. Methylation and gene expression data combined with survival analysis was used to identify LUAD-specific, methylation-driven lncRNAs and mRNAs for predicting the diagnosis and prognosis of LUAD.

\footnotetext{
Abbreviations

LncRNA: long noncoding RNA; LUAD: lung adenocarcinoma; GO: gene ontology; NSCLC: non-small-cell lung cancer; FC: fold change; FDR: false discovery rate; TCGA: The Cancer Genome Atlas Project; DAVID: The Database for Annotation, Visualization and Integrated Discovery; ROC: receiver operating curve; AUC: area under the ROC curve.
}

\section{Acknowledgements} Not applicable.

\section{Authors' contributions}

RL and YQQ, HL conceived and designed the study. YEY, YHY and MYZ collected the literature. RL drafted the manuscript, and $Y Q Q$ and $H L$ revised the manuscript. All authors read and approved the final manuscript.

\section{Funding}

This work was supported by Grants from the Major Scientific and Technological Innovation Project of Shandong Province (2018CXGC1212), the Science and Technology Foundation of Shandong Province (2014GSF118084 and 2016GSF121043), the Medical and Health Technology Innovation Plan of Jinan City (201805002) and the National Natural Science Foundation of China (81372333).

\section{Availability of data and materials}

All data are available from the sources listed in the manuscript--the TCGA data portal.

\section{Ethics approval and consent to participate}

Consent for participation from all patients was obtained through The Cancer Genome Atlas Project.

\section{Consent for publication}

Not applicable.

\section{Competing interests}

The authors declare that they have no competing interests.

\section{Author details}

${ }^{1}$ Department of Respiratory and Critical Care Medicine, Qilu Hospital of Shandong University, Jinan 250012, China. ${ }^{2}$ Department of Clinical Laboratory, Qianfoshan Hospital of Shandong Province, Jinan 250014, China.

Received: 18 January 2019 Accepted: 14 September 2019 Published online: 27 September 2019

\section{References}

1. Hirsch FR, Scagliotti GV, Mulshine JL, Kwon R, Curran WJ, Wu Y-L, et al. Lung cancer: current therapies and new targeted treatments. Lancet. 2017;389:299-311.

2. Yang Z, Liu B, Lin T, Zhang Y, Zhang L, Wang M. Multiomics analysis on DNA methylation and the expression of both messenger RNA and microRNA in lung adenocarcinoma. J Cell Physiol. 2019:234:7579-86.

3. Yoshizawa A, Motoi N, Riely GJ, Sima CS, Gerald WL, Kris MG, et al. Impact of proposed IASLC/ATS/ERS classification of lung adenocarcinoma: prognostic subgroups and implications for further revision of staging based on analysis of 514 stage I cases. Mod Pathol. 2011;24:653-64.

4. Hahn WC, Weinberg RA. Rules for making human tumor cells. N Engl J Med. 2002;347:1593-603.

5. Zheng SC, Breeze CE, Beck S, Teschendorff AE. Identification of differentially methylated cell types in epigenome-wide association studies. Nat Methods. 2018:15:1059-66.

6. Sadikovic B, Al-Romaih K, Squire JA, Zielenska M. Cause and consequences of genetic and epigenetic alterations in human cancer. Curr Genomics. 2008;9:394-408.

7. Bernstein $B E$, Meissner $A$, Lander ES. The mammalian epigenome. Cell. 2007;128:669-81.

8. Ferry L, Fournier A, Tsusaka T, Adelmant G, Shimazu T, Matano S, et al. Methylation of DNA ligase 1 by G9a/GLP recruits UHRF1 to replicating DNA and regulates DNA methylation. Mol Cell. 2017;67(550-565):e555.

9. Zheng $\mathrm{X}$, Zhang $\mathrm{N}, \mathrm{Wu} \mathrm{H}-\mathrm{J}$, Wu H. Estimating and accounting for tumor purity in the analysis of DNA methylation data from cancer studies. Genome Biol. 2017:18(1):17. https://doi.org/10.1186/s13059-016-1143-5.

10. Cui C, Gan Y, Gu L, Wilson J, Liu Z, Zhang B, et al. P16-specific DNA methylation by engineered zinc finger methyltransferase inactivates gene transcription and promotes cancer metastasis. Genome Biol. 2015;16:252. https://doi.org/10.1186/s13059-015-0819-6. 
11. Heyn H, Vidal E, Ferreira HJ, Vizoso M, Sayols S, Gomez A, et al. Epigenomic analysis detects aberrant super-enhancer DNA methylation in human cancer. Genome Biol. 2016;17:11. https://doi.org/10.1186/s13059-016-0879-2.

12. Wang Y-P, Zhou W, Wang J, Huang X, Zuo Y, Wang T-S, et al. Arginine methylation of $\mathrm{MDH} 1$ by CARM1 inhibits glutamine metabolism and suppresses pancreatic cancer. Mol Cell. 2016;64:673-87.

13. Xie W, Kagiampakis I, Pan L, Zhang YW, Murphy L, Tao Y, et al. DNA methylation patterns separate senescence from transformation potential and indicate cancer risk. Cancer Cell. 2018;33(309-321):e305.

14. Tong Y, Sun J, Wong CF, Kang Q, Ru B, Wong CN, et al. MICMIC: identification of DNA methylation of distal regulatory regions with causal effects on tumorigenesis. Genome Biol. 2018;19(1):73. https://doi.org/10.1186/ s13059-018-1442-0.

15. Saito K, Kawakami K, Matsumoto I, Oda M, Watanabe G, Minamoto T. Long interspersed nuclear element 1 hypomethylation is a marker of poor prognosis in stage IA non-small cell lung cancer. Clin Cancer Res. 2010;16:2418-26.

16. He J, Wu K, Guo C, Zhou J-K, Pu W, Deng Y, et al. Long non-coding RNA AFAP1-AS1 plays an oncogenic role in promoting cell migration in nonsmall cell lung cancer. Cell Mol Life Sci. 2018;75:4667-81.

17. Cedoz P-L, Prunello M, Brennan K, Gevaert O, Berger B. MethylMix 2.0: an $\mathrm{R}$ package for identifying DNA methylation genes. Bioinformatics. 2018;34:3044-6.

18. Gevaert O, Tibshirani R, Plevritis SK. Pancancer analysis of DNA methylation-driven genes using MethylMix. Genome Biol. 2015;16:17.

19. Gao C, Zhuang J, Li H, Liu C, Zhou C, Liu L, et al. Exploration of methylation-driven genes for monitoring and prognosis of patients with lung adenocarcinoma. Cancer Cell Int. 2018;18:194. https://doi.org/10.1186/ s12935-018-0691-z.

20. Teschendorff AE, Breeze CE, Zheng SC, Beck S. A comparison of referencebased algorithms for correcting cell-type heterogeneity in EpigenomeWide Association Studies. BMC Bioinformatics. 2017;18(1):105. https://doi. org/10.1186/s12859-017-1511-5.

21. Webster AP, Plant D, Ecker S, Zufferey F, Bell JT, Feber A, et al. Increased DNA methylation variability in rheumatoid arthritis-discordant monozygotic twins. Genome Med. 2018;10(1):64. https://doi.org/10.1186/s1307 3-018-0575-9.

22. Sanford T, Meng MV, Railkar R, Agarwal PK, Porten SP. Integrative analysis of the epigenetic basis of muscle-invasive urothelial carcinoma. Clin Epigenetics. 2018;10:19. https://doi.org/10.1186/s13148-018-0451-x.

23. Ritchie ME, Phipson B, Wu D, Hu Y, Law CW, Shi W, et al. limma powers differential expression analyses for RNA-sequencing and microarray studies. Nucleic Acids Res. 2015;43:e47.

24. Pan $Y$, Song $Y$, Cheng $L, X u H$, Liu J. Analysis of methylation-driven genes for predicting the prognosis of patients with head and neck squamous cell carcinoma. J Cell Biochem. 2019. https://doi.org/10.1002/jcb.29252.

25. Lu T, Chen D, Wang Y, Sun X, Li S, Miao S, et al. Identification of DNA methylation-driven genes in esophageal squamous cell carcinoma: a study based on The Cancer Genome Atlas. Cancer Cell Int. 2019;19:52. https://doi.org/10.1186/s12935-019-0770-9.

26. Li GX, Ding ZY, Wang YW, Liu TT, Chen WX, Wu JJ, et al. Integrative analysis of DNA methylation and gene expression identify a six epigenetic driver signature for predicting prognosis in hepatocellular carcinoma. J Cell Physiol. 2019;234:11942-50.

27. Shi X, Sun M, Liu H, Yao Y, Song Y. Long non-coding RNAs: a new frontier in the study of human diseases. Cancer Lett. 2013;339:159-66.

28. Duruisseaux M, Esteller M. Lung cancer epigenetics: from knowledge to applications. Semin Cancer Biol. 2018;51:116-28.

29. Juergens RA, Wrangle J, Vendetti FP, Murphy SC, Zhao M, Coleman B, et al. Combination epigenetic therapy has efficacy in patients with refractory advanced non-small cell lung cancer. Cancer Discov. 2011;1:598-607.

30. Tomasetti M, Amati M, Neuzil J, Santarelli L. Circulating epigenetic biomarkers in lung malignancies: from early diagnosis to therapy. Lung Cancer. 2017;107:65-72.

31. Darılmaz GY, Ortaç EE. Lung cancer and epigenetic modifications. Tuberkuloz ve Toraks. 2016:64:163-70.

32. Mehta A, Dobersch S, Romero-Olmedo AJ, Barreto G. Epigenetics in lung cancer diagnosis and therapy. Cancer Metastasis Rev. 2015;34:229-41.

33. Diaz-Lagares A, Crujeiras AB, Lopez-Serra P, Soler M, Setien F, Goyal A, et al. Epigenetic inactivation of the p53-induced long noncoding RNA TP53 target 1 in human cancer. Proc Natl Acad Sci. 2016;113:E7535-44.
34. Deng J, Mueller M, Geng T, Shen Y, Liu Y, Hou P, et al. H19 IncRNA alters methylation and expression of Hnf4a in the liver of metformin-exposed fetuses. Cell Death Dis. 2017:8:e3175.

35. Heilmann K, Toth R, Bossmann C, Klimo K, Plass C, Gerhauser C. Genomewide screen for differentially methylated long noncoding RNAs identifies Esrp2 and IncRNA Esrp2-as regulated by enhancer DNA methylation with prognostic relevance for human breast cancer. Oncogene. 2017;36:6446-61

36. Mohammad F, Pandey GK, Mondal T, Enroth S, Redrup L, Gyllensten U, et al. Long noncoding RNA-mediated maintenance of DNA methylation and transcriptional gene silencing. Development. 2012;139:2792-803.

37. Feng $\mathrm{N}$, Ching T, Wang Y, Liu B, Lin H, Shi O, et al. Analysis of microarray data on gene expression and methylation to identify long non-coding RNAs in non-small cell lung cancer. Sci Rep. 2016;6:37233.

38. Lu KH, Li W, Liu XH, Sun M, Zhang ML, Wu WQ, et al. Long non-coding RNA MEG3 inhibits NSCLC cells proliferation and induces apoptosis by affecting p53 expression. BMC Cancer. 2013;13:461.

39. Zhang W, Huang C, Gong Z, Zhao Y, Tang K, Li X, et al. Expression of LINC00312, a long intergenic non-coding RNA, is negatively correlated with tumor size but positively correlated with lymph node metastasis in nasopharyngeal carcinoma. J Mol Histol. 2013;44:545-54.

40. Sun M, Liu XH, Lu KH, Nie FQ, Xia R, Kong R, et al. EZH2-mediated epigenetic suppression of long noncoding RNA SPRY4-IT1 promotes NSCLC cell proliferation and metastasis by affecting the epithelial-mesenchymal transition. Cell Death Dis. 2014;5:e1298.

41. Li W, Sun M, Zang C, Ma P, He J, Zhang M, et al. Upregulated long noncoding RNA AGAP2-AS1 represses LATS2 and KLF2 expression through interacting with EZH2 and LSD1 in non-small-cell lung cancer cells. Cell Death Dis. 2016;7:e2225.

42. Lu W, Zhang H, Niu Y, Wu Y, Sun W, Li H, et al. Long non-coding RNA linc00673 regulated non-small cell lung cancer proliferation, migration, invasion and epithelial mesenchymal transition by sponging miR-150-5p. Mol Cancer. 2017;16:118.

43. Xie Y, Zhang Y, Du L, Jiang X, Yan S, Duan W, et al. Circulating long noncoding RNA act as potential novel biomarkers for diagnosis and prognosis of non-small cell lung cancer. Mol Oncol. 2018;12:648-58.

44. Chen Z, Chen X, Chen P, Yu S, Nie F, Lu B, et al. Long non-coding RNA SNHG20 promotes non-small cell lung cancer cell proliferation and migration by epigenetically silencing of P21 expression. Cell Death Dis. 2017;8:e3092.

45. Chen J, Hu L, Wang J, Zhang F, Chen J, Xu G, et al. Low expression LncRNA TUBA4B is a poor predictor of prognosis and regulates cell proliferation in non-small cell lung cancer. Pathol Oncol Res. 2016;23:265-70.

46. Nie FQ, Sun M, Yang JS, Xie M, Xu TP, Xia R, et al. Long noncoding RNA ANRIL promotes non-small cell lung cancer cell proliferation and inhibits apoptosis by silencing KLF2 and P21 expression. Mol Cancer Ther. 2014;14:268-77.

47. Han L, Zhang EB, Yin DD, Kong R, Xu TP, Chen WM, et al. Low expression of long noncoding RNA PANDAR predicts a poor prognosis of non-small cell lung cancer and affects cell apoptosis by regulating $\mathrm{BCl}-2$. Cell Death Dis. 2015:6:e1665.

48. Wang X, Zhou J, Xu M, Yan Y, Huang L, Kuang Y, et al. A 15-IncRNA signature predicts survival and functions as a ceRNA in patients with colorectal cancer. Cancer Manage Res. 2018;10:5799-806.

49. Kim O, Yoon JH, Choi WS, Ashktorab H, Smoot DT, Nam SW, et al. GKN2 contributes to the homeostasis of gastric mucosa by inhibiting GKN1 activity. J Cell Physiol. 2014;229:762-71.

50. Marcucci G, Yan P, Maharry K, Frankhouser D, Nicolet D, Metzeler KH, et al. Epigenetics meets genetics in acute myeloid leukemia: clinical impact of a novel seven-gene score. J Clin Oncol. 2014;32:548-56.

51. Krick S, Shi S, Ju W, Faul C, Tsai SY, Mundel P, et al. Mpv17l protects against mitochondrial oxidative stress and apoptosis by activation of Omi/HtrA2 protease. Proc Natl Acad Sci. 2008;105:14106-11.

52. Gevaert O. MethylMix: an R package for identifying DNA methylationdriven genes. Bioinformatics. 2015;31:1839-41.

\section{Publisher's Note}

Springer Nature remains neutral with regard to jurisdictional claims in published maps and institutional affiliations. 